\title{
Estudo das propriedades físicas e mecânicas de concreto com substituição parcial de agregado miúdo por resíduo agrícola
}

Atualmente, o aproveitamento de resíduos na construção civil tem sido estimulado, uma vez que esse setor apresenta como um dos maiores consumidores de materiais naturais em seus processos e produtos. Objetiva-se com esse trabalho avaliar a adição de resíduos de sabugo de milho para a produção do concreto. Fazendo com que o mesmo possa se tornar um grande auxiliador na produção de materiais alternativos de menor custo, substituindo em parte os agregados naturais, normalmente empregados na fabricação de artefatos de concreto. Os resíduos do milho, especificamente o sabugo, foram triturados, peneirados conforme a granulometria da areia, e substituídos no concreto. $\mathrm{O}$ traço utilizado foi obtido junto uma tabela de resistência, sofrendo algumas modificações. Foram confeccionados ao mesmo tempo lotes testemunhos e lotes com substituição do agregado miúdo. Este trabalho avaliou o comportamento físico e mecânico do concreto com adição de resíduos de sabugo de milho na proporção de $3 \%$ da massa de areia, comparando com o concreto convencional. A substituição do agregado miúdo pelo agregado miúdo reciclado obteve redução nos resultados de resistência média, portanto, não descaracteriza o potencial promissor do resíduo de sabugo de milho como matéria-prima alternativa para uso em concretos não estruturais.

\section{Study of physical and mechanical concrete properties with partial replacement of aggregate for agricultural}

\begin{abstract}
Currently, the use of waste in construction has been stimulated, since this sector presents as one of the largest consumers of natural materials in its processes and products. The objective of this work is to evaluate the addition of corn cob residue to the concrete production. By enabling them to become a great help in the production of lower cost alternative materials, replacing in part the natural aggregates normally used in the manufacture of concrete artifacts. The maize residues, specifically the cob, were transferred by a rural producer from Lavras, Minas Gerais, were crushed, sifted according to the granulometry of the sand, and replaced in the concrete. The trait used was obtained together with a resistance table, undergoing some modifications. At the same time, batches of batches and batches were made with replacement of the small aggregate. This work evaluated the physical and mechanical behavior of concrete with the addition of corn cob residues in the proportion of $3 \%$ of the sand mass, compared to conventional concrete. The replacement of the small aggregate by the recycled kid aggregate obtained a reduction in the results of average resistance, therefore, it does not de-characterize the potential of the corn cob residue as an alternative raw material for use in non-structural concretes.
\end{abstract}

Keywords: Composite; Waste; Corn cob; Lignocellulosic material; Civil construction

Topic: Engenharia de Materiais

Reviewed anonymously in the process of blind peer
Received: $11 / 03 / 2020$

Approved: 22/04/2020
Douglas Lamounier Faria (iD)

Universidade Federal de Lavras, Brasil http://lattes.cnpq.br/2575514568061593 http://orcid.org/0000-0002-5405-8430 douglas.lamounier@yahoo.com

Tony Matheus Carvalho Eugenio (ib Universidade Federal de Lavras, Brasil http://lattes.cnpq.br/0823437440133853 http://orcid.org/0000-0001-7049-2862 tony.matheus@hotmail.com

Laércio Mesquita Júnior (iD Universidade Federal de Lavras, Brasil http://lattes.cnpq.br/9672446731312267 http://orcid.org/0000-0002-4122-1390 laerciomjr@gmail.com

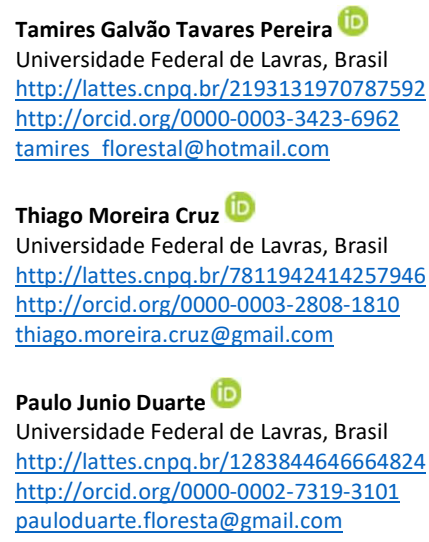

Tamires Galvão Tavares Pereira (D) Universidade Federal de Lavras, Brasil http://lattes.cnpq.br/2193131970787592 http://orcid.org/0000-0003-3423-6962 tamires florestal@hotmail.com

Thiago Moreira Cruz (iD)

Universidade Federal de Lavras, Brasi http://lattes.cnpq.br/7811942414257946 http://orcid.org/0000-0003-2808-1810 thiago.moreira.cruz@gmail.com

Paulo Junio Duarte (iD

Universidade Federal de Lavras, Brasil http://lattes.cnpq.br/1283844646664824

http://orcid.org/0000-0002-7319-3101 pauloduarte.floresta@gmail.com

\author{
Thiago de Paula Protásio (iD) \\ Universidade Federal Rural da Amazônia, Brasil \\ http://lattes.cnpq.br/3847639263484797 \\ http://orcid.org/0000-0002-5560-8350 \\ thiago.protasio@ufra.edu.br \\ Lourival Marin Mendes (iD \\ Universidade Federal de Lavras, Brasil \\ http://lattes.cnpq.br/1846557273818913 \\ http://orcid.org/0000-0001-8713-405X \\ lourivall@ufla.br \\ José Benedito Guimarães Junior (ic \\ Universidade Federal de Lavras, Brasil \\ http://lattes.cnpq.br/5497377793349287 \\ http://orcid.org/0000-0002-9066-1069 \\ jose.guimaraes@ufla.br
} T.; CRUZ, T. M.; DUARTE, P. J.; PROTÁSIO, T. P.; MENDES, L. M.; GUIMARÃES JUNIOR, J. B.. Estudo das propriedades físicas $\mathrm{e}$ mecânicas de concreto com substituição parcial de agregado miúdo por resíduo agrícola. Revista Ibero Americana de Ciências Ambientais, v.11, n.3, p.184-197, 2020. DOI: 


\section{INTRODUÇÃO}

A indústria da construção civil é responsável por grande parte do consumo dos recursos naturais extraídos do planeta. Com isso, a utilização de resíduos como matéria prima na construção civil pode vir a reduzir a quantidade de recursos naturais retirados do meio ambiente. Isto porque os resíduos não reciclados são depositados em aterros sanitários que ocupam espaços cada vez mais valorizados, especialmente aqueles próximos aos grandes centros urbanos.

A utilização de materiais sustentáveis na produção de elementos construtivos é uma alternativa para redução do impacto ambiental do setor da construção civil, que apresenta alguns indicadores preocupantes quanto ao consumo de recursos não renováveis, gasto energético e geração de resíduos sólidos (SANTOS et al., 2017).

Porém, as diferenças entre as propriedades dos agregados naturais e reciclados trazem uma cautela quanto as suas utilizações, bem como à confiabilidade dos mesmos em se tratando de obras de grande responsabilidade, como é o caso do concreto estrutural. Pode-se notar entre diferenças a heterogeneidade da composição (diversidade de fases constituintes) e a menor resistência mecânica.

A consequência das peculiaridades dos agregados reciclados no concreto é que este, além de estar propenso a apresentar variabilidade em suas propriedades, tende a ser menos trabalhável, menos resistente, mais deformável (menor módulo de elasticidade), mais poroso e assim mais permeável. Assim, de acordo com Mehta et al. (2008), a escolha dos materiais de construção no futuro deverá atender ao quádruplo enfoque iniciado pela letra E: Engenharia, Economia, Energia e Ecologia.

A exemplo para este quádruplo de engenharia do futuro, pesquisas com a utilização de resíduos agroindustriais na construção civil, principalmente os poluentes, contribuem para este quadro de engenharia do futuro. Arroz, trigo e milho representam as maiores colheitas em se tratando de cereais. As partes não reaproveitáveis destes cereais como, folhas, sabugo, caule e casca, são considerados lixo, e por seu volume, contribuem para um dos maiores problemas ambientais: a destinação inadequada dos resíduos agroindustriais. A escolha pelo uso dos resíduos de milho pode se justificar pela facilidade de obtenção do resíduo e devido à quantidade gerada anualmente no país.

Segunda a Companhia Nacional de Abastecimento (CONAB, 2018), a produção de grãos na safra 2017/2018, em fase de colheita, deve voltar ao nível histórico com produção de 232 milhões de toneladas, apesar do decréscimo de 2,1\% em comparação à safra passada, que chegou a 237,7 milhões de toneladas. Nesse contexto, o objetivo desse trabalho foi avaliar a adição de resíduos da cultura do milho, especificamente o sabugo, para a produção de concreto, visando à produção de materiais alternativos de menor custo, substituindo em grande parte os agregados naturais, normalmente empregados na fabricação de artefatos de concreto.

\section{MATERIAL E MÉTODOS}

O presente estudo foi desenvolvido em partes no laboratório de Materiais de Construção Civil do 
Centro Universitário de Lavras - UNILAVRAS e, em partes, na Unidade Experimental de Painéis de Madeira UEPAM/UFLA, ambos localizados na cidade de Lavras/MG. A influência da adição dos resíduos de sabugo de milho no concreto de Cimento Portland foi estudada a partir de ensaios físicos e mecânicos realizados em corpos-de-prova moldados com concreto contendo 0 e $3 \%$ de adição de resíduos de sabugo de milho em relação a massa de areia, bem como em ensaio de hidratação do cimento a fim de se verificar se houve inibição do processo de cura do cimento com a adição de resíduos de sabugo de milho.

Foram utilizados como matéria prima para produção do concreto: cimento Portland CP V - ARI/Plus de alta resistência inicial como aglutinante mineral, areia natural de origem quartzosa, brita de origem granítica e os resíduos da cultura do milho fornecidos por um produtor rural localizado na cidade de Lavras/MG.

Para avaliar uma possível interferência dos extrativos presentes nos resíduos de sabugo de milho no concreto, foi realizada a determinação dos extrativos nos resíduos da cultura do milho e ensaio de hidratação do cimento afim de se determinar a classificação do resíduo de acordo com o índice de inibição. Para a remoção dos extrativos totais, os resíduos de sabugo de milho foram moídos e classificados em peneiras mecânicas. A amostra selecionada foi aquela que passou pela peneira de 1,83 $\mathrm{mm}$ e ficou retida na peneira de $1,69 \mathrm{~mm}$.

Foram pesadas 5 gramas de amostra seca de resíduos de sabugo de milho em papel filtro poroso, previamente seco e tarado em balança analítica com resolução de 0,0001 g. O papel filtro com a amostra foram colocados em um extrator soxhlet, e a extração foi realizada de acordo com a NBR 14853 (ABNT, 2010), em que primeiramente a extração foi realizada com álcool etílico/tolueno (1:2 v/v) por um período de tempo de 6 horas após o primeiro refluxo, em seguida a extração foi realizada com álcool etílico por 6 horas após o primeiro refluxo, permitindo a secagem das amostras à atmosfera após cada extração. Em seguida, o papel filtro com a amostra foram lavados com água quente em abundância até a verificação de coloração transparente da água, indicando a não-remoção de outros componentes. As amostras foram secas em estufa a $103{ }^{\circ} \mathrm{C} \pm 2{ }^{\circ} \mathrm{C}$ por um período de 24 horas ou até massa constante; retiradas da estufa, armazenadas em um dessecador até atingir a temperatura ambiente e pesadas. Utilizaram-se, para esta análise, quatro repetições.

O método utilizado para avaliar a inibição das partículas de resíduos de sabugo de milho com o cimento foi o utilizado por Hofstrand et al. (1984), sofrendo algumas modificações. Para Mori et al. (2007), esse ensaio consiste em mensurar, de forma sistemática, a evolução da temperatura da mistura cimentomaterial lignocelulósico durante certo período de tempo. O monitoramento dessa temperatura de reação é utilizado como parâmetro para se determinar índices de inibição da 'pega' ou endurecimento.

Para esse ensaio foram misturados 15 gramas de partículas de sabugo de milho secas, 200 gramas de cimento Portland CP V-ARI/Plus e $90 \mathrm{~mL}$ de água. Após homogeneizados, sem exceder o prazo de 5 minutos, esses materiais foram inseridos no interior de caixas de isopor com dimensões internas de $80 \times 97$ $x 56 \mathrm{~mm}$ (comprimento $x$ largura $x$ altura, respectivamente) e espessura das paredes de $7,5 \mathrm{~mm}$; as quais 
foram previamente forradas com papel alumínio visando diminuir ao máximo a perda de temperatura para o ambiente. Dentro de cada caixa de isopor foi inserido um sensor conectado a um Datalogger, no qual os dados gerados foram armazenados em intervalos de um segundo, durante um período de 24 horas.

Cada caixa de isopor, com a mistura e o sensor para medição da temperatura foram acondicionados em uma caixa térmica (Figura 1), forrada com lã de vidro, a fim de evitar a perda de calor para o ambiente, uma vez que as reações que ocorrem com a mistura de cimento-partículas lignocelulósicas e água são exotérmicas. Em seguida, iniciou-se a aquisição dos dados.

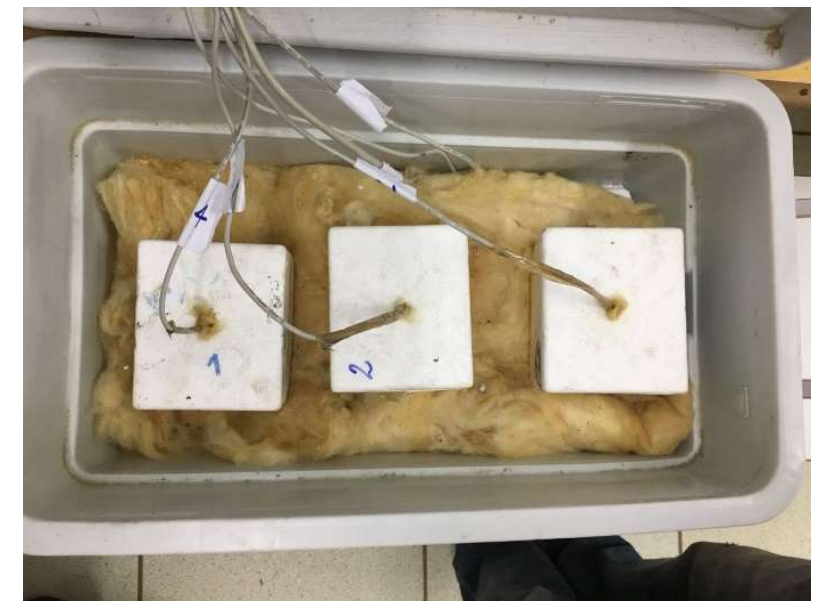

Figura 1: Sistema para armazenar as amostras para o ensaio de inibição do concreto.

A caixa térmica e o sistema de aquisição dos dados se encontravam dentro de uma sala climatizada com temperatura de $20 \pm 1{ }^{\circ} \mathrm{C}$ e umidade relativa de $60 \pm 5 \%$ para garantir ainda mais a não interferência da temperatura externa no interior das caixas térmicas. $O$ ensaio foi realizado em triplicata, em que foram empregadas partículas de resíduos de sabugo de milho que passaram pela peneira de abertura 4,9 mm e ficaram retidas na peneira de abertura 2,4 mm. O índice de inibição foi calculado utilizando a Equação 2 apresentada por Okino et al. (2004):

$$
\mathrm{I}=\{[\mathrm{TCIM}-\mathrm{TM}) / \mathrm{TCIM}][\mathrm{HM}-\mathrm{HCIM}) / \mathrm{HCIM}][(\mathrm{SCIM}-\mathrm{SM}] \mathrm{X} 100\}
$$

Em que: I = índice de hidratação da cura do cimento (\%); $\mathrm{T}_{\mathrm{CIM}}=$ temperatura máxima da mistura cimento/água $\left({ }^{\circ} \mathrm{C}\right)$; $\mathrm{T}_{\mathrm{M}}=$ temperatura máxima da mistura material lignocelulósico/cimento/água $\left({ }^{\circ} \mathrm{C}\right)$; $\mathrm{H}_{\mathrm{CIM}}=$ tempo para atingir a temperatura máxima de hidratação do cimento na mistura cimento/água (h); $\mathrm{H}_{\mathrm{M}}=$ tempo para atingir a temperatura máxima da mistura de hidratação do cimento na mistura material lignocelulósico/cimento/água ( $\mathrm{h})$; $\mathrm{S}_{\mathrm{CIM}}=$ máximo incremento de temperatura da curva na mistura cimento/água $\left({ }^{\circ} \mathrm{C} / \mathrm{h}\right)$; $\mathrm{S}_{\mathrm{M}}=$ máximo incremento de temperatura da curva na mistura material lignocelulósico/cimento/água $\left({ }^{\circ} \mathrm{C} / \mathrm{h}\right)$. O efeito da inibição da cura do cimento é classificado de acordo com a Tabela 1. A influência da adição dos resíduos de sabugo de milho no concreto foi estudada a partir da confecção de 72 corpos de prova cilíndricos de dimensões 10 × 20cm (Figura 2), distribuídos em 36 corpos de prova para cada traço, destes, foram rompidos 12 corpos de prova aos 1, 7, 14 e aos 28 dias, sendo 6 corpos de prova para compressão axial e 6 corpos de prova para tração por compressão diametral para cada idade. Foram confeccionados 24 corpos de prova para ensaios físicos, sendo 6 corpos de prova para ensaios aos 1, 7, 14 e 28 dias, para as 
propriedades de absorção de água, índice de vazios e massa específica.

Tabela 1: Classificação do material lignocelulósico de acordo com o índice de inibição obtido.

\begin{tabular}{|l|l|}
\hline ÍNDICE DE INIBIÇÃO (\%) & CLASSIFICAÇÃo \\
\hline $\mathrm{I}<10$ & Baixa inibição \\
\hline $\mathrm{I}=10$ a 50 & Moderada inibição \\
\hline $\mathrm{I}=50$ a 100 & Alta inibição \\
\hline $\mathrm{I}>100$ & Extrema inibição \\
\hline
\end{tabular}

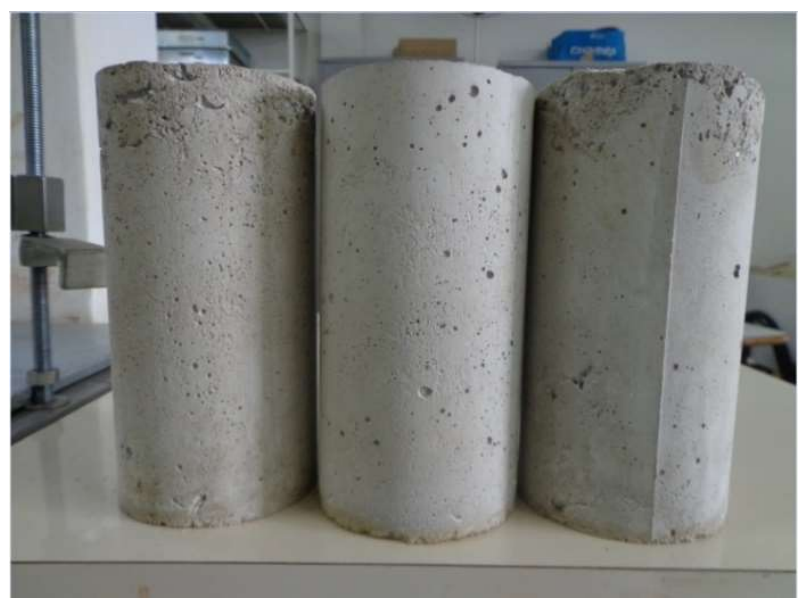

Figura 2: Corpos de prova de concreto confeccionados com e sem adição de resíduos de sabugo de milho.

A caracterização dos materiais foi realizada de acordo com a NBR 7211 (ABNT, 2009), que estabelece as dimensões máximas e mínimas dos agregados. O método utilizado para o controle granulométrico foi o peneiramento mecânico, com peneiras de 50 x 50cm e malha de abertura específica para cada material. 0 agregado miúdo utilizado foi areia média natural, de origem quartzosa, peneirada em peneira de malha 2,4 mm e o agregado graúdo foi composto por brita granítica. Com relação ao agregado graúdo utilizou-se duas frações do material, sendo $50 \%$ de brita um, dimensões entre 4,7 a $25 \mathrm{~mm}$.

Os resíduos de sabugo de milho utilizados na confecção dos corpos de prova, após processo de moagem, foram apenas aqueles que apresentaram dimensões características entre 2,4 e 4,9 mm, de forma a padronizar as dimensões dos resíduos de sabugo de milho utilizados, pois a granulometria dos materiais se constitui fator determinante nos ensaios de resistência.

Para o processo de mistura do concreto, foi utilizada betoneira intermitente de eixo inclinado, com a seguinte ordem de colocação dos materiais: parte da água, brita 0 , brita 1 , areia, cimento, resíduo de sabugo de milho e o restante da água, deixando misturar por cinco minutos antes do teste de consistência e mais dois minutos antes da confecção dos corpos de prova.

A consistência do concreto foi determinada pelo abatimento do tronco de cone (slump test), de acordo com a NBR NM 67 (ABNT, 1998), afim de se verificar as condições de trabalhabilidade dos concretos produzidos. Para sua execução, fazem-se necessários uma base metálica plana quadrada, um molde troncocônico e uma haste metálica de seção circular. Foi estabelecido, em função da trabalhabilidade, o abatimento médio de $120 \mathrm{~mm}$ com variação de + ou - $20 \mathrm{~mm}$ para cada um dos dois tipos de concreto produzidos (0 e 3\%). Na Tabela 2 é apresentada a composição dos traços utilizados, juntamente com seus respectivos valores teste de abatimento pelo tronco de cone e teor de ar incorporado. 
Tabela 2: Composição final dos traços dos concretos.

\begin{tabular}{|l|l|l|l|l|l|l|l|}
\hline \multirow{2}{*}{ TRAÇO } & CIMENTO & AREIA & $\begin{array}{l}\text { BRITA } \\
\mathbf{0}\end{array}$ & $\begin{array}{l}\text { BRITA } \\
\mathbf{1}\end{array}$ & ÁGUA & SABUGO & $\begin{array}{l}\text { ENSAIO DE ABATIMENTO PELO TRONCO DE } \\
\text { CONE (MM) }\end{array}$ \\
\cline { 2 - 7 } & $------------\left(K G / M^{3}\right)$ & ---------- & 125,00 \\
\hline Referência & 350,31 & 881,1 & 477,7 & 477,7 & 253,71 & - & 110,00 \\
\hline $3 \%$ & 350,31 & 854,56 & 477,7 & 477,7 & 253,71 & 26,43 & \\
\hline
\end{tabular}

$\mathrm{O}$ adensamento foi realizado manualmente, realizou-se o adensamento em duas camadas com 12 golpes com haste cilíndrica para cada camada, sem atingir o fundo do molde na primeira camada, e na segunda, de forma a atingir aproximadamente $200 \mathrm{~mm}$ da camada inferior, de acordo com a NBR 5738 (ABNT, 2015). A cura foi realizada em tanque de água saturada com hidróxido de cálcio, conforme estabelecido na NBR 5738 (ABNT, 2008).

Os corpos de prova foram ensaiados à compressão axial conforme a NBR 5739 (ABNT, 2007), que prescreve um método de ensaio pelo qual devem ser ensaiados os corpos de prova cilíndricos de concreto, moldados conforme a NBR 5738 (ABNT, 2015) e extraídos conforme a NBR 7680 (ABNT, 2007). O ensaio foi realizado com corpos de prova de 1, 7, 14 e 28 dias de idade, em prensa hidráulica SOLOTEST com capacidade de 100 tf. Com carga aplicada continuamente, e velocidade de carregamento de aproximadamente $4 \mathrm{kN} / \mathrm{s}$. Para a realização do ensaio, os corpos de prova foram retirados do tanque de cura, eliminando-se o excesso de água, e colocados na prensa para o rompimento (Figura 3).

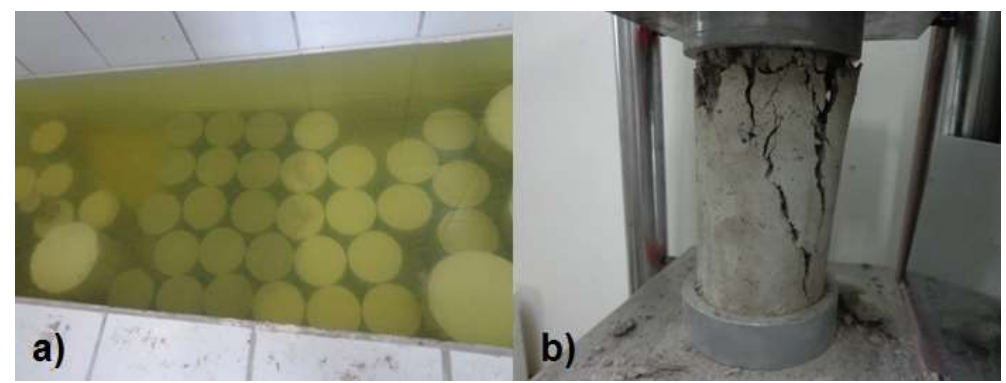

Figura 3: a) Corpos de prova em tanque com água saturada com hidróxido de cálcio; b) Corpo de prova sendo rompido em ensaio de compressão axial em prensa hidráulica.

Na verificação da resistência à tração por compressão diametral, os corpos de prova foram ensaiados a 1, 7, 14 e 28 dias de idade, de acordo com a NBR 7222 (ABNT, 2011). Os corpos de prova permaneceram em cura submersa até o momento do ensaio. $O$ excesso de água foi eliminado antes da colocação dos corpos de prova na prensa. O tempo entre a retirada do tanque e o rompimento do último corpo de prova foi de aproximadamente 20 minutos para cada teste realizado. Na Figura 4 apresentada abaixo é possível ver o esquema utilizado para determinação da resistência à tração por compressão diametral.

Os corpos de prova foram ensaiados de acordo com a NBR 9778 (ABNT, 2009) para a determinação da absorção de água, índice de vazios e massa específica. Primeiramente, foram pesados os corpos de prova na balança à temperatura ambiente e, em seguida, foram colocados em estufa a $103 \stackrel{\circ}{\circ} \pm 2 \stackrel{\circ}{\circ}$ por um período de 72 horas. Em seguida, foram aferidas as massas secas dos corpos de prova, e após anotação dos dados, foram imersas as amostras em água por um período de 72 horas. Após completar a etapa de saturação, as amostras foram colocadas em um recipiente cheio de água, para determinação da massa saturada.

A temperatura do recipiente foi progressivamente levada à ebulição, num intervalo de 15 a 30 
minutos. As amostras ficaram durante 5 horas em ebulição, mantendo constante o volume de água. Em seguida, foram retiradas as amostras do recipiente, e imersas num recipiente completo com água à temperatura ambiente (Figura 5), para medição da massa saturada, com auxílio de balança hidrostática. Após pesagem do corpo de prova, o mesmo foi retirado da água, enxugado e, em seguida, foi aferida sua massa saturada.

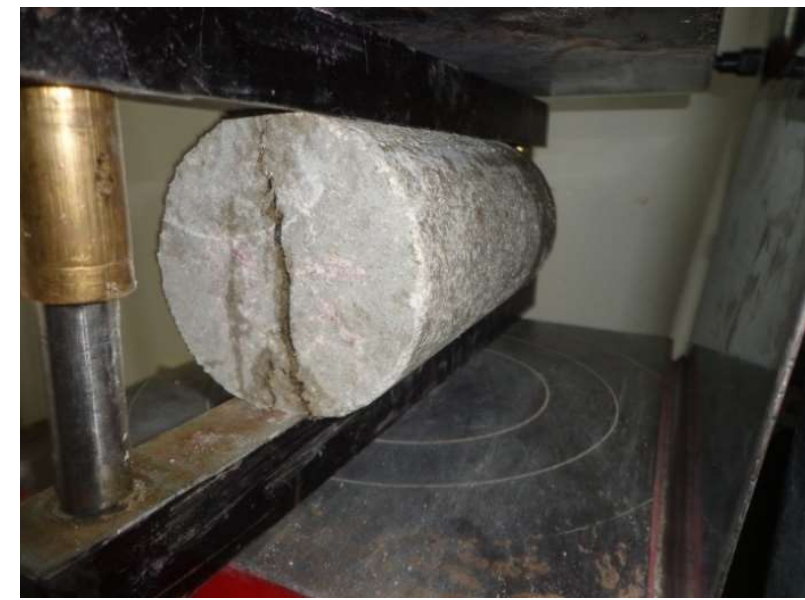

Figura 4: Posicionamento do corpo de prova no aparato para determinação da resistência à tração por compressão diametral.

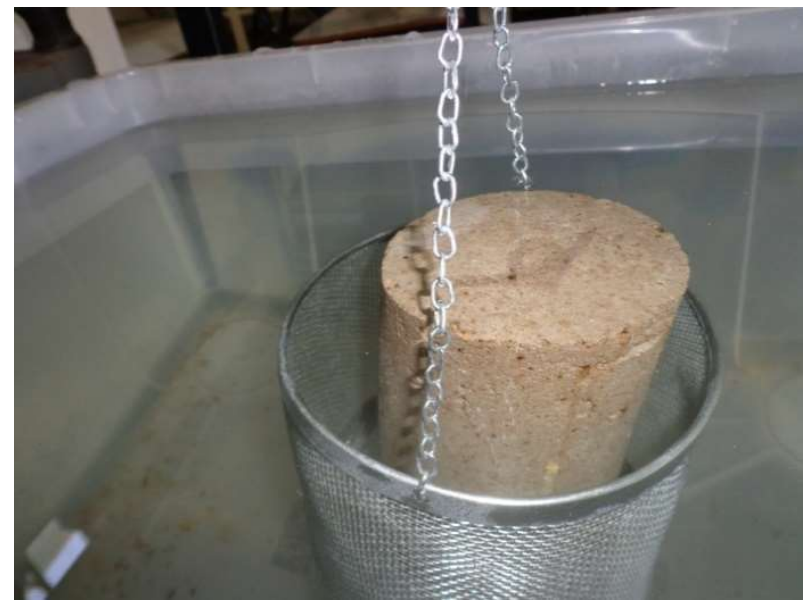

Figura 5: Corpo de prova submerso para leitura da massa hidrostática.

Para a análise dos dados, foi realizado teste Tukey entre as médias encontradas em cada tipo de ensaio, com índice de significância de 0,05 , para o desdobramento da interação tempo de cura $x$ tipo de concreto. Além disso, foi realizada a análise de regressão, chegando a uma equação polinomial de segunda ordem, em que os resultados foram melhor apresentados.

\section{RESULTADOS E DISCUSSÃO}

A análise química das partículas de sabugo de milho apresentou valores médios de teor de extrativos de 3,37\%. A composição química do material lignocelulósico em estudo pode ser o principal fator de impedimento da viabilização da manufatura dos compósitos cimentícios (MORI et al., 2007). De acordo com Simatupang et al. (1978), os extrativos presentes na madeira e nos materiais lignocelulósicos são os principais responsáveis pela inibição da solidificação do cimento, sendo seus princípios ativos os compostos fenólicos e os carboidratos livres. Ramos et al. (2011) caracterizando os resíduos de biomassa vegetal obtiveram teores médios de extrativos totais de 5,85\% para o sabugo de milho, valores semelhantes aos obtidos por Scatolino et al. (2013), que reportaram valores médios de 7,0\% de extrativos totais no sabugo de milho. Os teores de extrativos encontrados para o sabugo de milho influenciaram nos resultados obtidos pelo ensaio de inibição, o que pode ser comprovado pela análise em questão. Na Figura 6, é possível ver a curva de hidratação do cimento que exibe a temperatura atingida pela pasta de cimento em função do tempo.

Da Figura 6 observa-se que há inibição da pasta de cimento com a adição de partículas de sabugo de milho. De acordo com os cálculos realizados, o índice de inibição das partículas dos resíduos de sabugo de milho foi de $77,0 \%$. A partir da Figura 6 , verifica-se que a temperatura máxima atingida pela mistura sabugo 
de milho e cimento foi em torno de $35^{\circ} \mathrm{C}$, distante da temperatura máxima da pasta de cimento e água, que foi em torno de $67^{\circ} \mathrm{C}$. Nota-se que a temperatura máxima e o tempo de hidratação da mistura de sabugo de milho foram, baixa e elevado, respectivamente, em relação à temperatura máxima e ao tempo da pasta de cimento-água, confirmando o alto índice de inibição e a incompatibilidade com o cimento.

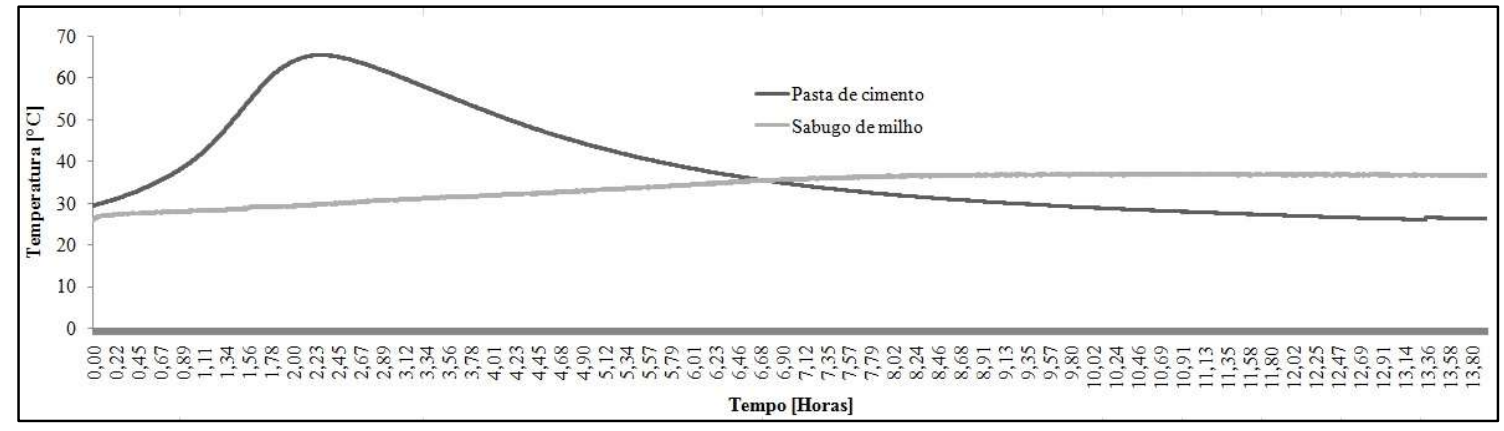

Figura 6: Curva de hidratação da pasta de cimento e da pasta com resíduos de sabugo de milho.

Observa-se que a pasta contendo resíduos de sabugo de milho não conseguiu atingir a temperatura de hidratação do cimento, apresentando também valores muito inferiores de variação de temperatura por hora, além de exibir um tempo necessário para atingir a temperatura máximo muito superior ao tratamento sem nenhuma partícula lignocelulósica. Esse comportamento resultou em um elevado índice de inibição do material, que apresentou valor de 77\%, sendo classificado de acordo com a Tabela 1, como de alta inibição. A Tabela 3 apresenta o resultado do teste Tukey para o desdobramento da interação tempo de cura $x$ tipo de concreto para ensaio de resistência à compressão axial.

Tabela 3: Resultado do teste Tukey com nível de significância de 5\% para ensaio de resistência à compressão axial.

\begin{tabular}{|l|l|l|l|l|}
\hline \multirow{2}{*}{ TRATAMENTO } & \multicolumn{4}{|l|}{ TEMPO DE CURA (DIAS) } \\
\cline { 2 - 5 } & $\mathbf{1}$ & $\mathbf{7}$ & $\mathbf{1 4}$ \\
\cline { 2 - 5 } & RESISTÊNCIA À COMPRESSÃO AXIAL (MPA) & $\mathbf{2 8}$ \\
\hline Sem adição (0\%) & $10,32^{(1,01) *} \mathrm{a}$ & $21,98^{(0,87)} \mathrm{a}$ & $23,94^{(0,74)} \mathrm{a}$ & $25,84^{(1,76)} \mathrm{a}$ \\
\hline Com adição (3\%) & $2,43^{(0,02)} \mathrm{b}$ & $3,31^{(0,39)} \mathrm{b}$ & $6,68^{(0,38)} \mathrm{b}$ & $7,06^{(0,42)} \mathrm{b}$ \\
\hline
\end{tabular}

Médias seguidas da mesma letra não diferem entre si pelo teste Tukey a $5 \%$ de significância. *Valores entre parênteses representam o desvio padrão.

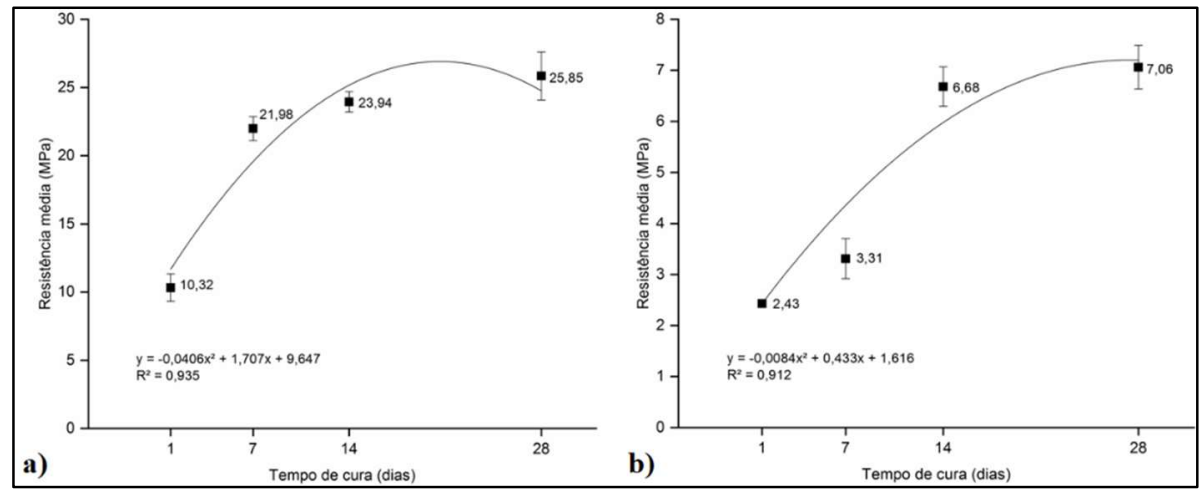

Figura 7: a) e b) Resistência à compressão axial dos corpos de prova de concreto com $0 \%$ e $3 \%$ de resíduos em função do tempo.

Observa-se na Tabela 3 que houve diferença significativa ao nível de 5\% de probabilidade entre a resistência à compressão axial obtida no concreto sem adição (0\%) e com adição (3\%) em todos os tempos de cura. É fato também que com adição de resíduos de sabugo de milho na proporção testada, a resistência 
média do concreto foi bem inferior àquela com o concreto sem adição de resíduos. Esta queda de resistência ocorreu entre \pm 250 e $500 \%$ em alguns tempos de cura. A função que descreve o comportamento do concreto em função do tempo em corpos de prova testemunhas e com adição de $3 \%$ de resíduos de sabugo de milho à mistura se encontra na Figura 7.

A resistência à compressão axial dos corpos de prova de concreto apresentou comportamento parabólico para todas as idades avaliadas, nos dois tratamentos estudados. Nota-se na Tabela 2 que houve diferença significativa entre os tratamentos avaliados, em todos tempos de cura. Houve um acréscimo de resistência ao longo do tempo, apresentando um comportamento partindo de 10,32 até 25,84 MPa para o concreto sem adição (0\%) e 2,43 até 7,06 MPa (3\%). Essa diferença de resistência à compressão axial pode ser explicada pela Figura 6, que mostra a inibição da hidratação do cimento causada pelos extrativos presentes nos resíduos de sabugo de milho. Comportamentos semelhantes foram observados por Santos et al. (2017). Os autores avaliaram o uso de agregado miúdo reciclado em matrizes cimentícias com fibras de sisal e obtiveram resultados variando entre 15,78 a 31,27 MPa, em matrizes e com adição de 4 e $6 \%$ de fibras de sisal. For Fernandes et al. (2015) trabalhando com cinza de bagaço de cana-de-açúcar (CBC) observaram valores para concretos, referência de 30,0 e 42,5 MPa para 7 e 28 dias de idade, respectivamente. Já para concretos contendo $5 \%$ de $\mathrm{CBC}$, os autores resultaram em valores variando entre 27,5 e $35 \mathrm{MPa}$, para 7 e 28 dias de idade, respectivamente.

A resistência à compressão axial é uma das principais propriedades do concreto, uma vez que em conjunto com a armadura, o compósito passa a se tornar resistente às solicitações normais de compressão e tração, devido ao concreto e ao aço, respectivamente. A Tabela 4 apresenta o resultado do teste Tukey para o desdobramento da interação tempo de cura $x$ tipo de concreto para resistência à tração por compressão diametral.

Tabela 4: Resultado do teste Tukey com nível de significância de 5\% para ensaio de resistência à tração por compressão diametral.

\begin{tabular}{|l|l|l|l|l|}
\hline \multirow{2}{*}{ Tratamento } & \multicolumn{4}{|l|}{ Tempo de cura (dias) } \\
\cline { 2 - 5 } & 1 & 7 & 14 & 28 \\
\cline { 2 - 5 } & RESISTÊNCIA À TRAÇÃO POR COMPRESSÃO AXIAL (MPA) & $12,65^{(0,40)} \mathrm{a}$ \\
\hline Sem adição (0\%) & $5,89^{(0,81) *} \mathrm{a}$ & $10,68^{(0,15)} \mathrm{a}$ & $10,91^{(1,06)} \mathrm{a}$ & $4,14{ }^{(0,09)} \mathrm{b}$ \\
\hline Com adição (3\%) & $1,65^{(0,28)} \mathrm{b}$ & $2,40^{(0,35)} \mathrm{b}$ & $3,52^{(0,33)} \mathrm{b}$ & \\
\hline
\end{tabular}

Médias seguidas da mesma letra não diferem entre si pelo teste Tukey a 5\% de significância. *Valores entre parênteses representam o desvio padrão.

Observa-se na Tabela 4 que houve diferença significativa ao nível de $5 \%$ de probabilidade entre a resistência à tração por compressão diametral obtida no concreto sem adição (0\%) e com adição (3\%) em todos os tempos de cura. É fato também que com adição de resíduos de sabugo de milho na proporção testada, a resistência à compressão axial média do concreto foi bem inferior àquela com o concreto sem adição de resíduos. Esta queda de resistência ocorreu entre \pm 250 e $300 \%$ em alguns tempos de cura.

Procedendo-se a análise de regressão entre as médias encontradas se chega a função que descreve o comportamento do concreto em função do tempo em corpos de prova testemunhas e com adição de $3 \%$ de resíduos de sabugo de milho à mistura para o ensaio de resistência à tração por compressão diametral. 
Esta relação está expressa na Figura 8 a) e b).

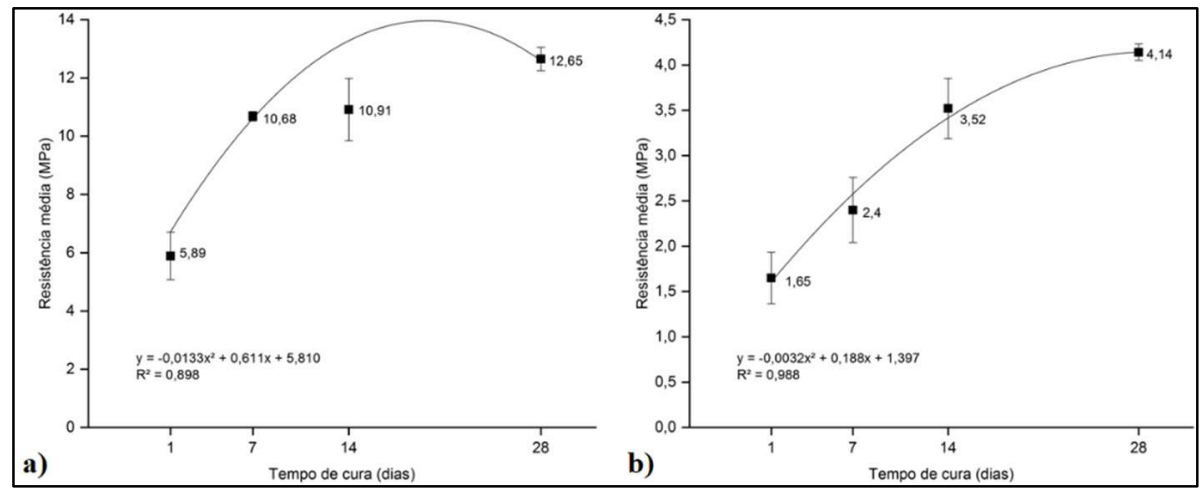

Figura 8: a) e b) Resistência à tração por compressão diametral dos corpos de prova de concreto com $0 \%$ e $3 \%$ de resíduos em função do tempo.

Para a resistência à tração por compressão diametral, os concretos estudados nesse trabalho apresentaram o mesmo comportamento descrito acima. Foi observado resistências médias variando entre 5,89 e 12,65 MPa para concretos sem adição (0\%) e 1,65 e 4,14 MPa para concretos com 3\% de adição, respectivamente. Mais uma vez os resultados podem ser explicados pela interferência que os extrativos realizaram na hidratação do cimento. Essa possível interferência também pôde ser observada por Santos et al. (2017), obtendo resistências médias variando de 1,88 a 2,23 MPa em matrizes e com adição de 4 e $6 \%$ de fibras de sisal. A Tabela 5 apresenta o resultado do teste Tukey para o desdobramento da interação tempo de cura $\mathrm{x}$ tipo de concreto para absorção de água.

Tabela 5: Resultado do teste Tukey com nível de significância de 5\% para ensaio de absorção de água.

\begin{tabular}{|c|c|c|c|c|}
\hline \multirow[t]{3}{*}{ TRATAMENTO } & \multicolumn{4}{|c|}{ TEMPO DE CURA (DIAS) } \\
\hline & 1 & 7 & 14 & 28 \\
\hline & \multicolumn{4}{|c|}{ ABSORÇÃO DE ÁGUA (\%) } \\
\hline Sem adição (0\%) & $8,66^{(0,75)} \mathrm{a}$ & $9,53^{(0,23)} \mathrm{a}$ & $10,66^{(0,89)} \mathrm{a}$ & $12,67^{(1,26)} \mathrm{a}$ \\
\hline Com adição (3\%) & $10,06^{(0,65)} \mathrm{b}$ & $11,05^{(0,32) ~ b}$ & $12,27^{(0,43)} \mathrm{b}$ & $12,07^{(1,15)} \mathrm{a}$ \\
\hline
\end{tabular}

Médias seguidas da mesma letra não diferem entre si pelo teste Tukey a 5\% de significância. Valores entre parênteses representam o desvio padrão.

Observa-se que houve diferença significativa ao nível de $5 \%$ de probabilidade entre a absorção de água obtida no concreto sem adição (0\%) e com adição (3\%) em todos os tempos de cura. Procedendo-se a análise de regressão entre as médias encontradas se chega a função que descreve o comportamento do concreto em função do tempo em corpos de prova testemunhas e com adição de $3 \%$ de resíduos de sabugo de milho à mistura no ensaio de absorção de água. Esta relação está expressa na Figura 9 a) e b).

Para os ensaios de absorção de água e índice de vazios, apenas o tempo de cura de 28 dias não apresentou diferença estatística. Para absorção de água os resultados variaram de 8,66 a 12,67\% para concretos sem adição (0\%) e 10,06 a 12,07\% para aqueles com adição (3\%); para índice de vazios, foram obtidos valores entre 18,07 a $22,71 \%$ para compósitos sem adição (0\%) e 20,36 a 23,96\% para aqueles com $3 \%$ de adição em massa. Analisando o tempo de imersão dos corpos de prova, verifica-se que a tendência apresentada pelos concretos com e sem adição de resíduos de sabugo de milho foi de estabilizar a propriedade de absorção de água por volta de $12,0 \%$ e a propriedade de índice de vazios por volta de $23,0 \%$ 
ao final dos 28 dias. Inicialmente, nos primeiros dias de imersão dos corpos de prova em água, houve uma maior absorção por parte dos corpos de prova contendo adições, esse fato se deve ao caráter hidrofílico dos resíduos vegetais utilizados na pesquisa, porém após saturação das partículas, a absorção de água e o índice de vazios se mostraram estatisticamente iguais.

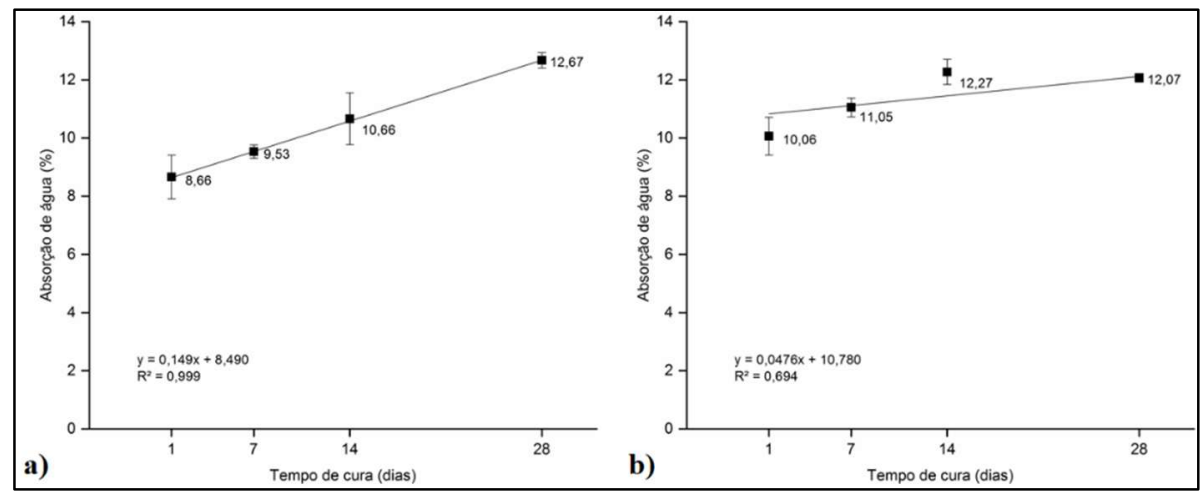

Figura 9: a) e b) Absorção de água dos corpos de prova de concreto com $0 \%$ e $3 \%$ de resíduos em função do tempo.

Esse comportamento também foi observado por Tafarel et al. (2016), resultando em valores de absorção de água de 5,60, 6,10 e 7,10\% para concretos testemunhos, com 5 e 10\% de incorporação do lodo, respectivamente. Os autores verificaram um aumento de 12 e $32 \%$ de absorção de água em concretos com a incorporação do lodo nos teores de 5 e 10\%, respectivamente. Vale ressaltar que a NBR 6136 (ABNT, 2006) estabelece limites de absorção média de até $10 \%$ para concreto com agregado natural, e, portanto, poderiam ser utilizados apenas concretos sem adição (0\%) com idades de 1 e 7 dias. Os resultados de absorção de água são bastante expressivos, uma vez que maiores teores de absorção de água estão diretamente ligados à porosidade do material e pode explicar a redução na resistência mecânica do material. A Tabela 6 apresenta o resultado do teste Tukey para o desdobramento da interação tempo de cura x tipo de concreto para índice de vazios.

Tabela 6: Resultado do teste Tukey com nível de significância de 5\% para ensaio de índice de vazios.

\begin{tabular}{|c|c|c|c|c|}
\hline \multirow[t]{3}{*}{ TRATAMENTO } & \multicolumn{4}{|c|}{ TEMPO DE CURA (DIAS) } \\
\hline & 1 & 7 & 14 & 28 \\
\hline & \multicolumn{4}{|c|}{ ÍNDICE DE VAZIOS (\%) } \\
\hline Sem adição (0\%) & $18,07^{(0,96)} \mathrm{a}$ & $19,18^{(0,43)} \mathrm{a}$ & $20,84^{(0,64)} \mathrm{a}$ & $22,71^{(1,53)} \mathrm{a}$ \\
\hline Com adição (3\%) & $20,36^{(1,05)} \mathrm{b}$ & $22,07^{(0,84)} \mathrm{b}$ & $22,64^{(0,89)} \mathrm{b}$ & $23,96^{(1,34)} \mathrm{a}$ \\
\hline
\end{tabular}

Médias seguidas da mesma letra não diferem entre si pelo teste Tukey a $5 \%$ de significância. Valores entre parênteses representam o desvio padrão.

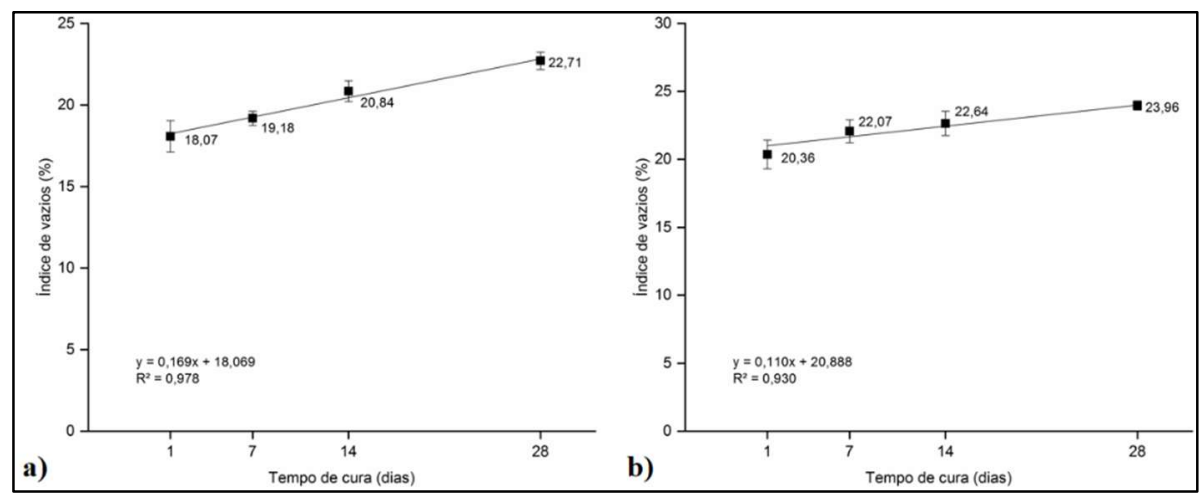

Figura 10: a) e b) Índice de vazios dos corpos de prova de concreto com 0\% e 3\% de resíduos em função do tempo. 
Observa-se que houve diferença significativa ao nível de 5\% de probabilidade entre o índice de vazios obtido no concreto sem adição (0\%) e com adição (3\%) em todos os tempos de cura. Procedendo-se a análise de regressão entre as médias encontradas se chega a função que descreve o comportamento do concreto em função do tempo em corpos de prova testemunhas e com adição de $3 \%$ de resíduos de sabugo de milho à mistura. Esta relação está expressa na Figura $10 \mathrm{a}$ ) e b).

A Tabela 7 apresenta o resultado do teste Tukey para o desdobramento da interação tempo de cura $x$ tipo de concreto para massa específica real.

Tabela 7: Resultado do teste Tukey com nível de significância de 5\% para massa específica real.

\begin{tabular}{|c|c|c|c|c|}
\hline \multirow[t]{3}{*}{ TRATAMENTO } & \multicolumn{4}{|c|}{ TEMPO DE CURA (DIAS) } \\
\hline & 1 & 7 & 14 & 28 \\
\hline & \multicolumn{4}{|c|}{ MASSA ESPECÍFICA REAL (G.CM-3) } \\
\hline Sem adição (0\%) & $2,54^{(0,09)} \mathrm{a}$ & $2,57^{(0,12)} \mathrm{a}$ & $2,64^{(0,19)} \mathrm{a}$ & $2,87^{(0,08)} \mathrm{a}$ \\
\hline Com adição (3\%) & $2,34^{(0,10)} \mathrm{b}$ & $2,36^{(0,07)} \mathrm{b}$ & $2,38^{(0,03)} \mathrm{b}$ & $2,53^{(0,15)} \mathrm{b}$ \\
\hline
\end{tabular}

Médias seguidas da mesma letra não diferem entre si pelo teste Tukey a 5\% de significância. Valores entre parênteses representam o desvio padrão.

Observa-se que houve diferença significativa ao nível de $5 \%$ de probabilidade entre a massa específica real obtida no concreto sem adição (0\%) e com adição (3\%) em todos os tempos de cura. Procedendo-se a análise de regressão entre as médias encontradas se chega a função que descreve o comportamento do concreto em função do tempo em corpos de prova testemunhas e com adição de $3 \%$ de resíduos de sabugo de milho à mistura. Esta relação está expressa na Figura 11 a) e b).

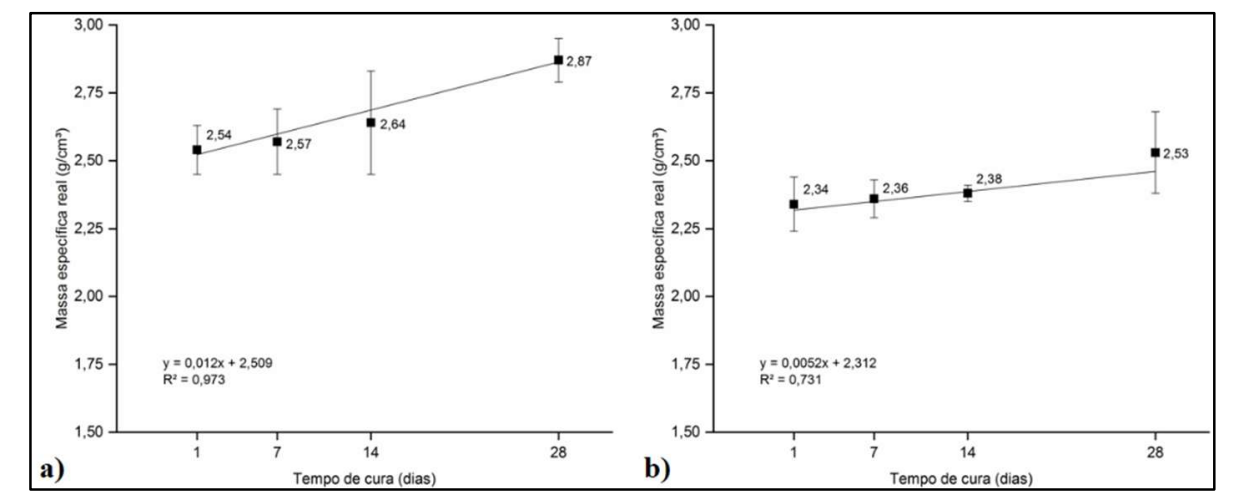

Figura 11: a) e b) Massa específica real dos corpos de prova de concreto com $0 \%$ e $3 \%$ de resíduos em função do tempo.

Os resultados obtidos para a massa específica real variaram entre 2,54 e $2,87 \mathrm{~g} \cdot \mathrm{cm}^{-3}$ para os corpos de prova sem adições ( $0 \%$ e entre 2,34 e $2,53 \mathrm{~g} \cdot \mathrm{cm}^{-3}$ para aqueles com $3 \%$ de adições de resíduos de sabugo de milho, ambos para as idades entre 1 e 28 dias. Valores semelhantes foram obtidos por Carrijo (2005), trabalhando com resíduos de construção e demolição visando avaliar o desempenho mecânico do concreto, obtendo valores entre 2,26 e $2,62 \mathrm{~g} . \mathrm{cm}^{-3}$ para concretos de diferentes traços.

\section{CONCLUSÕES}

A partir dos resultados obtidos para teor de extrativos e índice de inibição da cura do cimento dos resíduos de sabugo de milho, foi possível justificar o comportamento dos corpos de prova com adição de 
resíduos. Houve resultado positivo apenas nos corpos de prova testemunhos, que atenderam as normas vigentes em relação à resistência à compressão simples, resistência à compressão diametral, índice de vazios, massa específica e absorção de água.

Quando realizado o ensaio de resistência à compressão simples nos corpos de prova com resíduos, foi observado que nenhum corpo de prova, variando o tempo de cura de 1 a 28 dias, atenderam a resistência utilizada para concreto estrutural de $25 \mathrm{MPa}$, excluindo a possibilidade de emprego do concreto com resíduos para essa finalidade. Porém, os corpos de prova com adição de resíduos apresentaram resistência à compressão simples de 6,38 MPa, o suficiente para utilização em concreto sem função estrutural.

AGRADECIMENTOS: à Universidade Federal de Lavras (UFLA), ao Centro Universitário de Lavras (UNILAVRAS), à Fapemig, CAPES e CNPq pelo financiamento desse trabalho.

\section{REFERÊNCIAS}

ABNT. Associação Brasileira de Normas Técnicas. NBR 14853: Madeira: determinação do material solúvel em etanol-tolueno e em diclorometano e em acetona. Rio de Janeiro: ABNT, 2010.

ABNT. Associação Brasileira de Normas Técnicas. NBR 5738: Concreto: Procedimentos para moldagem e cura de corposde-prova. Rio de Janeiro: ABNT, 2015.

ABNT. Associação Brasileira de Normas Técnicas. NBR 5739: Concreto: Ensaio de compressão de corpos-de-prova cilíndricos. Rio de Janeiro: ABNT, 2007.

ABNT. Associação Brasileira de Normas Técnicas. NBR 6136: Blocos vazados de concreto simples para alvenaria: Requisitos. Rio de Janeiro: ABNT, 2016.

ABNT. Associação Brasileira de Normas Técnicas. NBR 7211: Agregados para concreto: Especificação. Rio de Janeiro: ABNT, 2009.

ABNT. Associação Brasileira de Normas Técnicas. NBR 7222: Concreto e argamassa - Determinação da resistência à tração por compressão diametral de corpos-de-prova cilíndricos. Rio de Janeiro: ABNT, 2011.

ABNT. Associação Brasileira de Normas Técnicas. NBR 76801: Concreto - Extração, preparo, ensaio e análise de testemunhos de estruturas de concreto Parte 1: Resistência à compressão axial. Rio de Janeiro: ABNT, 2015.

ABNT. Associação Brasileira de Normas Técnicas. NBR 9778: Argamassa e concreto endurecidos: Determinação da absorção de água, índice de vazios e massa específica. Rio de Janeiro: ABNT, 2009.

ABNT. Associação Brasileira de Normas Técnicas. NBR NM 67: Concreto: Determinação da consistência pelo abatimento do tronco de cone. Rio de Janeiro: ABNT, 1998.

CARRIJO, P. M.. Análise da influência da massa específica de agregados graúdos provenientes de resíduos de construção e demolição no desempenho mecânico do concreto.
Dissertação (Mestrado em Engenharia Civil) - Universidade de São Paulo, São Paulo, 2005.

CONAB. Companhia Nacional de Abastecimento. Acompanhamento da safra brasileira de grãos, v. 5 - Safra 2017/2018, n.8 - Oitavo Levantamento. Brasília, 2018.

FERNANDES, S. E.; TASHIMA, M. M.; MORAES, J. C. B.; ISTUQUE, D.; FIORITI, C. F.; MELGES, J. L. P.; AKASAKI, J. L.. Cinza de bagaço de cana-de-açúcar (CBC) como adição mineral em concretos para verificação de sua durabilidade. Revista Matéria, Rio de Janeiro, v.20, n.4, p.909-923, 2015. DOI: http://doi.org/10.1590/S1517-707620150004.0096

HOFSTRAND, A. D.; MOSLEMI, A. A.; GARCIA, J. F.. Curing characteristics of particles from nine northern Rocky Mountain species mixed with Portland cement. Forest Products Journal, v.34, n.2, p.57-61, 1984.

MEHTA, P. K.; MONTEIRO, P. J. M.. Concreto: microestrutura, propriedades e materiais. São Paulo: Pini, 2008.

MORI, F. A.; LOPES, Y. L. V.; MENDES, L. M.; LATORRACA, J. V. F.. Estudo da compatibilidade entre a madeira e as cascas de Eucalyptus grandis e cimento Portland. Ciência Florestal, Santa Maria, v.17, n.3, p.257-264, 2007. DOI: http://dx.doi.org/10.5902/198050981957

NEVILLE, A. M.. Propriedades do Concreto. 2 ed. São Paulo: PINI, 1997.

OKINO, E. Y. A.; SOUZA, M. R.; SANTANA, M. A. E.; SOUSA, M. E.; TEIXEIRA, D. E.. Chapa aglomerada de cimentomadeira de Hevea brasiliensis müll. Arg. Revista Árvore, Viçosa, v.28, n.3, p.451-457, 2004. DOI: http://doi.org/10.1590/S0100-67622004000300016

RAMOS, L. E. P.; TRUGILHO, P. F.; NAPOLI, A.; BIANCHI, M. L.. Characterization of residues from plant biomass for use in energy generation. Cerne, Lavras, v.17, n.2, p.237-246, 2011. DOI: http://doi.org/10.1590/S0104-77602011000200012 
SANTOS, D. O. J.; FONTES, C. M. A.; LIMA, P. R. L.. Uso de agregado miúdo reciclado em matrizes cimentícias para compósitos reforçados com fibras de sisal. Revista Matéria, Rio de Janeiro, v.22, n.1, 2017. DOI:

http://doi.org/10.1590/s1517-707620170001.0133

SCATOLINO, M. V.; SILVA, D. W.; MENDES, R. F.; MENDES, L. M.. Use of maize cob for production of particleboard.

Ciência e Agrotecnologia, Lavras, v.37, n.4, p.330-337, 2013. DOI: http://doi.org/10.1590/S1413-70542013000400006
SIMATUPANG, M. H.; SCHWARZ, G. H.; BROKER, F. W.. Small scale plants for the manufacture of mineral-bonded wood composites. In: WORLD FORESTRY CONGRESS, 8. Anais. Jakarta, 1978.

TAFAREL, N. F.; MACIOSKI, G.; CARVALHO, K. Q.; NAGALLI, A.; FREITAS, D. C.; PASSIG, F. H.. Avaliação das propriedades do concreto devido à incorporação de lodo de estação de tratamento de água. Revista Matéria, Lavras, v.21, n.4, p.974-986, 2016. DOI: http://doi.org/10.1590/s1517$\underline{707620160004.0090}$

A CBPC - Companhia Brasileira de Produção Científica (CNPJ: 11.221.422/0001-03) detém os direitos materiais desta publicação. Os direitos referem-se à publicação do trabalho em qualquer parte do mundo, incluindo os direitos às renovações, expansões e disseminações da contribuição, bem como outros direitos subsidiários. Todos os trabalhos publicados eletronicamente poderão posteriormente ser publicados em coletâneas impressas sob coordenação da Sustenere Publishing, da Companhia Brasileira de Produção Científica e seus parceiros autorizados. Os (as) autores (as) preservam os direitos autorais, mas não têm permissão para a publicação da contribuição em outro meio, impresso ou digital, em português ou em tradução. 